\title{
ABANDONO DA NARRATIVA, ENSINO CENTRADO NO ALUNO E APRENDER A APRENDER CRITICAMENTE ${ }^{1}$
}

\section{DISCLAIMING THE NARRATIVE, STUDENT-CENTERED TEACHING, AND LEARNING HOW LEARN CRITICALLY}

\author{
Marco Antonio Moreira \\ Instituto de Física - UFRGS \\ Caixa Postal 15051 - Campus \\ 91501-970 Porto Alegre, RS, Brasil \\ moreira@if.ufrgs.br \\ www.moreira.if.ufrgs.br
}

\begin{abstract}
Resumo
Neste trabalho proponho o abandono da narrativa como modelo clássico de ensino e argumento em favor de um ensino centrado no aluno, com participação ativa do aluno em atividades colaborativas, voltado para o aprender a aprender e para a aprendizagem significativa crítica. Além de minha larga experiência como professor e autor (2004, 2005), o texto reflete principalmente as obras de Postman e Weingartner (1969), Carl Rogers (1969), D.B. Gowin (1981) e Don Finkel (2008). Não são propostas nem argumentos novos, mas podem servir de motivação aos que queiram, e possam, fazer mudanças no ensino.
\end{abstract}

Palavras-chave: abandono da narrativa, ensino centrado no aluno, aprender a aprender, aprendizagem significativa crítica.

\begin{abstract}
In this paper I propose the disclaim of the narrative as the classical teaching model in favor of a student centered approach, with active participation of the students in colaborative activities, aiming at learning how to learn and at a critical meaningful learning. In addition to my large experience as teacher and author $(2004,2005)$, this text reflects mainly the works of Postman and Weingartner (1969), Carl Rogers (1969), D.B. Gowin (1981), and Don Finkel (2008). The proposals and arguments are not new, but they may motivate those who can and are willing to change their teaching practices.
\end{abstract}

Keyword: disclaiming the narrative, student-centered teaching, learning how to learn, critical meaningful learning.

\section{O modelo da narrativa}

O modelo clássico de ensino, consagrado e aceito sem questionamento por professores, alunos e pais e pela sociedade em geral, é aquele em que o professor ensina, básica e fundamentalmente falando, dizendo aos estudantes o que se supõe que

1 Conferência proferida no II Encontro Nacional de Ensino de Ciências da Saúde e do Ambiente, Niterói, RJ, 12 a 15 de maio de 2010 e no VI Encontro Internacional e III Encontro Nacional de Aprendizagem Significativa, São Paulo, SP, 26 a 30 de julho de 2010. 
devam saber. Esse modelo é o que Don Finkel (2008) descreveu como Dar aula narrando, ao qual contrapõe o modelo de Dar aula de boca fechada (op.cit., p. 44), estimulando a busca de maneiras alternativas de ensinar.

Mas por que questionar um modelo tão aceito? Vejamos! Nesse modelo, muitas vezes baseado em um livro de texto, o professor escreve (uma forma de narrar) no quadro-de-giz aquilo que os alunos devem copiar em seus cadernos, estudar (memorizar) e depois reproduzir nas avaliações. Às vezes, o professor repete, no quadro-de-giz, trechos do próprio livro de texto e, ainda assim, os alunos copiam para estudar depois, geralmente na véspera das provas a fim de não os esquecer.

Certamente, muitos professores não se limitam a repetir no quadro-de-giz o que está nos livros; fazem esquemas, sínteses, trazem exemplos, explicam, fazem demonstrações, enfim, “dão boas aulas", segundo modelo clássico. Mesmo assim, os alunos copiam tudo o que podem para estudar depois.

Outros professores, geralmente considerados ótimos professores, até mesmo grandes professores, fazem excelentes exposições orais, encantam seus alunos explicando clara e cuidadosamente certos assuntos. Esses alunos saem da aula com a boa sensação de que entenderam o assunto. Se esse assunto for pedido nas provas da mesma maneira que o professor explicou, provavelmente, sair-se-ão bastante bem. Mas, se as questões implicarem aplicações do mesmo a situações novas, o resultado, possivelmente, será bastante pobre. É comum, nesses casos, os alunos dizerem que tal conteúdo não foi “dado" em aula.

O modelo continua igual se o professor usar datashow em suas exposições e deixar que os alunos copiem os arquivos eletrônicos em seus pendrives. Mesmo assim, eles terão que memorizar informações para reproduzi-las nas provas.

Independentemente de provas, quanto do que foi aprendido em boas aulas narrativas restará depois de alguns meses? Alguns anos! Será mesmo um mecanismo eficaz de ensino e aprendizagem?

No modelo clássico de ensino, independente de o professor escrever no quadrode-giz, de explicar oralmente, de usar slides PowerPoint, o que ele ou ela faz é narrar. O conceito de aula como narrativa é proposto por Don Finkel (2008, p.34): Nosso modelo natural de dar aula, antes de haver sido submetido a exame, é Narrar (escrito com maiúsculas para sugerir uma atividade arquetípica). O ato principal de dar aula é narrar clara e cuidadosamente aos estudantes algo que desconhecem previamente. $O$ conhecimento se transmite, imaginamos, por meio deste ato narrativo. 
Finkel argumenta que o modelo da narrativa parece natural a todos, ou seja, aos alunos, pais, professores, diretores, inclusive para quem não tem filhos na escola, nem vínculo com a escola, e, por isso mesmo, não é questionado. Mas deveria sê-lo: transmitir informação desde a cabeça do professor até o caderno do aluno, para que este transfira a informação do caderno para a sua cabeça para passar em exames é um objetivo inadequado de educação (op.cit., p.35). Esse modelo está voltado para a aprendizagem de informações específicas a curto prazo. Pouco resta dessa aprendizagem após algum tempo. Ao contrário, a educação deveria buscar aprendizagens relevantes, de longa duração, que alterassem para sempre nossa apreciação do mundo, aprofundando-a, ampliando-a, agudizando-a (op.cit., p.37). A esses objetivos poderíamos acrescentar a crítica, ou seja, apreciação crítica do mundo (Moreira, 2005).

Para esse autor, Narrar é um meio ineficaz (ibid.) para estimular a compreensão, ainda que ocupe o primeiro lugar na lista daquilo que fazem os professores. Para ele, a boa docência é aquela que cria circunstâncias que conduzem à aprendizagem relevante, duradoura. Na educação, a primazia deve ser da aprendizagem, não do ensino. Aprender é o objetivo e ensinar é um meio para este fim (op.cit., p.43).

Atualmente fala-se muito (outra vez!) em ensino centrado no aluno, em professor como mediador e em aprender a aprender. Se estivermos de acordo com estas diretrizes, certamente estaremos de acordo com Finkel que a narrativa não é a melhor forma de ensinar e teremos que rever nosso modelo de bom professor. Nessa linha, Finkel propõe a metáfora Dar aula com a boca fechada (op.cit., p.45), a qual ele usa para tornar problemáticas as suposições clássicas sobre a boa docência.

Se ensinar é um meio para facilitar a aprendizagem e se a narrativa não tem sido eficaz para isso, por que não abandoná-la? Basta refletir sobre o que nos restou dos conhecimentos aprendidos na escola para concluir que a narrativa é ineficaz. Algumas disciplinas que cursamos na escola parece que nem existiram. Não sobrou nada. Outras, como a Física, por exemplo, as pessoas têm até um certo prazer em dizer que não sabem nada. Por que, então, não fechar a boca e deixar o aluno falar?

Se os alunos estudam e memorizam rigorosamente a narrativa do professor, acertam as respostas esperadas nos exames e são aprovados nas avaliações, por que esquecem tão rapidamente os conhecimentos adquiridos no ano passado, ou na escola de um modo geral? Por que, depois de serem aprovados em exames altamente seletivos 
de ingresso à universidade chegam às disciplinas introdutórias de Física e Cálculo, por exemplo, como se nunca tivessem estudado os conhecimentos prévios necessários? Como se nada soubessem. A resposta é simples: a aprendizagem foi basicamente mecânica.

\section{A aprendizagem mecânica}

Aprendizagem mecânica (Ausubel, 2000; Moreira, 2006; Masini e Moreira, 2008; Valadares e Moreira, 2009) é aquela em que a nova informação é internalizada de maneira literal, sem interação cognitiva com conhecimentos prévios, sem incorporação à estrutura cognitiva. É simples memorização, sem compreensão. Pode ser reproduzida literalmente e aplicada a situações conhecidas, rotineiras. É útil para memorizar informações específicas que devem ser repetidas a curto prazo, como nas provas escolares. Mas se não forem usadas com frequência, rapidamente serão esquecidas.

Em contraposição à aprendizagem mecânica, define-se aprendizagem significativa como aquela em que há uma interação cognitiva entre os novos conhecimentos e conhecimentos prévios especificamente relevantes, existentes na estrutura cognitiva do ser que aprende. Os novos conhecimentos são internalizados de maneira substantiva e não-arbitrária. Substantiva quer dizer não ao pé-da-letra, nãoliteral; não-arbitrária indica que um novo conhecimento adquire significado não por interagir arbitrariamente com qualquer conhecimento prévio, mas sim com algum conhecimento em particular. Aprendizagem significativa é aprendizagem com significado, com compreensão, com capacidade de transferência, de aplicação a situações novas.

Aprendizagem significativa e aprendizagem mecânica não constituem uma dicotomia, quer dizer, a aprendizagem não é, necessariamente, ou significativa ou mecânica. As duas estão situadas nos extremos de um mesmo contínuo e, na prática, na escola, as aprendizagens situam-se em alguma região desse contínuo. O problema do modelo da narrativa é que ele, quase que invariavelmente, leva a uma aprendizagem situada na região da aprendizagem mecânica.

Mas, se há um contínuo entre aprendizagem mecânica e aprendizagem significativa, não poderia o aluno aprender inicialmente de forma um tanto mecânica e ir, progressivamente, dando significados aos novos conhecimentos, incorporando-os a sua estrutura cognitiva até chegar a uma aprendizagem significativa? De fato, isso pode acontecer. Mas geralmente não acontece. A aprendizagem significativa é progressiva, o 
que não implica que deva começar de forma mecânica. Também não implica que a progressividade ocorra naturalmente.

O problema é que o modelo da narrativa está associado a uma avaliação behaviorista, comportamentalista, que permeia a escola. $\mathrm{O}$ behaviorismo como referencial para organizar o ensino, amplamente dominante na época da tecnologia educacional, foi abandonado, pelo menos no discurso, em favor do construtivismo. $\mathrm{Na}$ abordagem comportamentalista, o professor define claramente, precisamente, objetivos operacionais, ou seja, comportamentos que o aluno deve ser capaz de apresentar após o ensino, coisas que o estudante deve ser capaz de fazer ou dizer. Se os comportamentos definidos forem apresentados, o aprendiz é aprovado na unidade de estudo, recebe o reforço positivo, e entra em outra etapa da modelagem, ao final da qual deverá exibir outros comportamentos previamente definidos. Contudo, exibir tais comportamentos não implica compreensão, atribuição de significados. Os estudantes podem apresentar os comportamentos desejados sem entender o que estão fazendo, sem dar sentido às situações, sem atribuir significados aos conhecimentos. São capazes apenas de aplicar os novos conhecimentos a situações conhecidas, ou seja, repetir aplicações dadas em aula pelo professor ou que aparecem nos materiais instrucionais.

Esta descrição da avaliação comportamentalista não é exagerada. Seguramente, Skinner propunha outra coisa, mas, na prática educacional, a abordagem skinneriana resulta, fortemente, em aprendizagem mecânica. Como foi dito antes, a proposta behaviorista foi abandonada, na escola, em favor de teorias e metodologias construtivistas. Melhor seria dizer abandonada no discurso, pois na prática predomina a narrativa, muito próxima ao comportamentalismo e, sobretudo, a avaliação comportamentalista: certo ou errado, sim ou não, sabe ou não sabe, exibe ou não exibe, tudo ou nada, ou seja, uma avaliação (na verdade, uma medição) dicotômica que não leva em conta a progressividade da aprendizagem construtivista.

Mesmo que os professores e as metodologias sejam construtivistas, a avaliação acaba tendo um viés behaviorista: alunos, pais, diretores, advogados cobram dos professores evidências documentais objetivas, ou seja, "provas" de que o estudante "sabe ou não sabe" alguma coisa. 


\section{O ensino centrado no aluno}

Ensino centrado no aluno, tendo o professor como mediador, é ensino em que o aluno fala muito e o professor fala pouco. Deixar os alunos falarem implica usar estratégias nas quais possam discutir, negociar significados entre si, apresentar oralmente ao grande grupo o produto de suas atividades colaborativas, receber e fazer críticas. O aluno deve ser ativo, não passivo. Ela ou ele tem que aprender a interpretar, a negociar significados; tem que aprender a ser crítica(o) e aceitar a crítica. Receber acriticamente a narrativa do "bom professor" não leva a uma aprendizagem significativa crítica, a uma aprendizagem relevante, de longa duração; não leva ao aprender a aprender.

Estas ideias não são novas. Foram já propostas por Carl Rogers, em 1969, na sua conhecida obra Feedom to learn (Liberdade para aprender), coincidentemente no mesmo ano em que Postman e Weingartner publicaram Teaching as a subversive activity (Ensino como atividade subversiva). Mas, na escola, os professores continuam narrando, dizendo aos alunos o que devem saber e reproduzir nas provas, sejam elas para passar de ano, para aprovar em exames nacionais ou para ingressar na Universidade. E todos, alunos, professores, pais, acham que isso é normal, que a escola é isso, sem se perguntarem o quanto nela se aprende de maneira significativa e crítica, o quanto se aprende para a cidadania, para a vida.

O abandono da narrativa implica a busca de maneiras de ensinar, nas quais, metaforicamente, o professor fale menos, narre menos, e o aluno fale mais, participe criticamente de sua aprendizagem. A narrativa (ou a leitura, se traduzirmos literalmente o termo lecture ainda usado em inglês para a aula expositiva) é uma metodologia de séculos passados, como se não estivéssemos no século XXI.

Centrar o ensino ou, melhor dizendo, a educação no estudante não significa, necessariamente, a não-diretividade rogeriana, mas sim organizá-lo de modo a ter em conta que o aluno é responsável por sua própria aprendizagem, que ele é senhor dessa aprendizagem.

Portanto, a aula não é o espaço e o momento para depositar (bancariamente, como dizia Freire, 1987, 1996) conhecimentos na cabeça do aluno, nem as avaliações são o instrumento para verificar o quanto ficou depositado e de que modo ficou. Por mais relevantes que sejam esses conhecimentos, o sujeito que aprende tem que perceber essa relevância e apresentar uma intencionalidade para aprender. O ser humano aprende 
de maneira significativa se tiver conhecimentos prévios adequados para isso e se quiser aprender. Como diz Maturana (2001), o professor, os materiais educativos, os novos conhecimentos, são perturbações externas de um sistema interno, um sistema autopoético (que se autorregula) que pode fazer mudanças estruturais em função dessas perturbações, mas não organizacionais. Quer dizer, o ser humano faz modificações na sua estrutura, mas não na sua organização. E é ele ou ela quem decide quais as modificações a serem feitas. Piaget (1976) também falava em autorregulação e organização. Ausubel (2000) dizia que o aluno deve apresentar uma predisposição para aprender. Já os primeiros behavioristas diziam que o sujeito deveria apresentar um set, ou uma prontidão, para determinado comportamento.

Ou seja, há muito que sabemos que é o aluno que decide se quer aprender significativamente ou não. Por que então insistir em um ensino centrado no professor, distante do aluno, e nele depositar, ou despejar, conhecimentos? É uma ilusão pensar que isso funciona. Ou é uma intenção para que não funcione.

Como foi dito, ensino centrado no aluno não precisa, ou não deve, ser interpretado como aquele em que o estudante tem total liberdade para escolher o que quer aprender. Ensino, currículo, aprendizagem e contexto são lugares comuns da educação (Schwab, 1973). Um evento educativo sempre envolve professor (ensino), conhecimento (currículo), aluno (aprendizagem) em um meio social (contexto). Quer dizer, sempre há um currículo, aqui entendido como os resultados pretendidos de aprendizagem (os Intended Learning Outcomes de Mauritz-Johnson, 1967), mas esse currículo não deve ser definido como uma série de conteúdos predeterminados que devem ser narrados aos alunos ou neles depositados. É preciso dar opções aos alunos, trabalhar os conteúdos através de situações que façam sentido para os alunos, que sejam relevantes para eles. São sempre eles que decidem se querem aprender algum conhecimento de modo significativo.

\section{A captação de significados}

D.B. Gowin (1981) propõe um modelo para episódios de ensino que encaixa muito bem no que foi dito na seção anterior. Seu modelo, segundo uma perspectiva de aprendizagem significativa, pode ser esquematizado tal como sugere a Figura 1. 


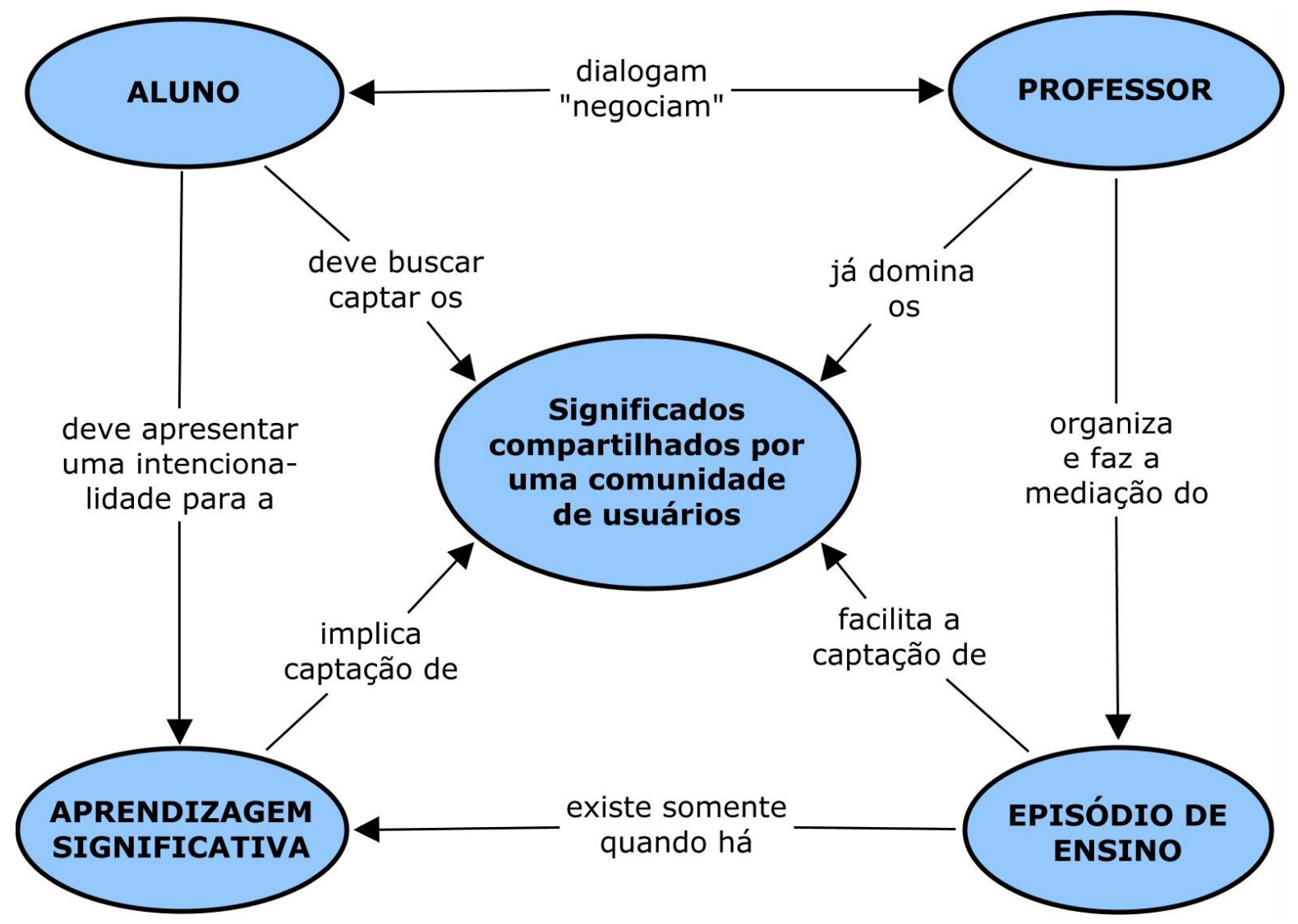

Figura 1. Um esquema para a captação de significados em um episódio de ensino (adaptado de Gowin, 1981).

Neste modelo, o professor, que já domina os significados aceitos no contexto da matéria da de ensino, apresenta esses significados ao aluno usando materiais educativos do currículo. Apresentar aqui não significa narrar, mas trazer tais significados ao aluno, através de diversas estratégias, de modo que ele ou ela perceba sua relevância e manifeste uma intencionalidade para captá-los e internalizá-los.

O aluno, por sua vez, deve devolver ao professor os significados que está captando a respeito dos conhecimentos que estão sendo trazidos através dos materiais educativos do currículo. Este comportamento do aluno depende de sua predisposição, de sua intencionalidade, para aprender. Esta, por sua vez, depende de sua percepção da relevância dos novos conhecimentos, de dar sentido às tarefas de aprendizagem. Outro fator limitante nessa linha é o que o aluno está imerso na cultura da narrativa, do monólogo do professor. Para o estudante, o esperado é que o professor fale, "dê aulas", não ele ou ela. É preciso, então, mudar, progressivamente, esta atitude discente através de estratégias instrucionais que levem o aluno a falar mais, ou seja, a externalizar para o professor os significados que está captando. 
Quando os significados externalizados pelo aluno não são aqueles que o professor pretendia que captasse, e que são aqueles aceitos no contexto da matéria de ensino, é preciso que o docente os apresente outra vez, de outra forma, e que o estudante volte a externalizá-los. Isto é, deve haver diálogo, interação social, intercâmbio de significados, negociação de significados. Em um episódio educativo deve haver sempre alguma forma de diálogo. O professor não deve ficar falando sozinho, narrando, enquanto o aluno apenas ouve e anota, quando não está distraído, pensando em outras coisas ou, até mesmo, cochilando.

A necessidade da interação social, diálogo, é também destacada por outros autores, muito reconhecidos, como Lev Vygotsky (1988) e Paulo Freire (1987, 1996). Cabe aqui mencionar que a linguagem tem um papel crucial nessa interação, nesse diálogo. Neil Postman (1969), por exemplo, destaca que a linguagem está totalmente implicada em toda e qualquer tentativa nossa de perceber a realidade (op.cit., p. 99).

Sem diálogo, sem interação social, seguimos no modelo da narrativa que, no início deste texto, concordando com os argumentos de Don Finkel (2008), consideramos ineficaz, inapropriado, para a educação.

O objetivo de toda essa interação envolvendo professor aluno e materiais educativos do currículo é o compartilhar significados. Enquanto esse objetivo não é atingido, enquanto o estudante não capta os significados, que são os aceitos no contexto da matéria de ensino, enquanto não compartilha esses significados com o professor, não há ensino. Só há ensino quando há captação de significados.

Um episódio de ensino ocorre quando o aluno capta os significados que o professor pretende que ele capte e que são aqueles já aceitos por uma comunidade de usuários, em um contexto que é o da matéria de ensino. (Gowin, 1981).

E, aí, voltamos à questão da intencionalidade, da disposição para aprender: uma vez captados os significados, é o aprendiz quem decide se vai incorporá-los de modo não-arbitrário e não-literal à sua estrutura cognitiva. É o estudante, como ser humano, como sistema autopoético, quem decide que mudanças fará na estrutura de seu aparato cognitivo, mantendo sua organização (Maturana, 2001). Os novos conhecimentos são perturbações que, na aprendizagem significativa, recebem significados (captados em função do ensino) e, ao mesmo tempo, em uma interação perturbadora modificam, em alguma medida, a estrutura dos conhecimentos prévios sem alterar sua organização. 


\section{Atividade colaborativas}

O ensino centrado no aluno implica não somente a relação dialógica, interacionista social, professor-aluno, mas também a interação aluno-aluno. Para isso, o ensino deve ser organizado de modo a prover situações que os alunos devem resolver colaborativamente, em pequenos grupos. Pode ser um projeto, um problema clássico (exemplar), um problema aberto, um mapa conceitual sobre determinado tópico, um diagrama $\mathrm{V}$ sobre um artigo de pesquisa, uma prática de laboratório, a análise crítica de um texto literário, uma dramatização. As possibilidades são muitas, o importante é que nessas atividades os alunos colaborem, discutam, discordem, busquem consensos. Tudo isso contribui para a captação de significados, para que o aluno sinta que o ensino está centrado nele, que o foco do ensino é a sua aprendizagem. Tais atividades estão sendo aqui propostas como presenciais, mas podem, também, ser desenvolvidas em ambientes virtuais de aprendizagem.

O resultado dessas atividades colaborativas deve ser apresentado ao grande grupo. Nessa ocasião, os integrantes do pequeno grupo submetem-se à crítica dos demais colegas. É um momento indispensável. A crítica é importante, a argumentação é importante, a autocrítica também o é. O resultado disso é que o grupo, quase que invariavelmente, reformula o que apresentou.

Novamente aqui é preciso levar em consideração que esse tipo de atividade não faz parte do esquema de ser aluno que o sujeito desenvolveu na escola ao longo de vários anos. No começo, os estudantes apresentarão resistências às atividades colaborativas em pequenos grupos. É necessário introduzi-las aos poucos e ter paciência.

As situações propostas aos alunos para serem resolvidas de modo colaborativo devem fazer sentido para eles, devem ser relevantes para eles. E, aí, o papel do professor é fundamental: é ele ou ela quem deve escolher cuidadosamente as situações. Além disso, o docente é o grande mediador da intensa interação social que decorre desse tipo de atividade, em sala de aula ou em ambientes virtuais.

Ensino centrado no aluno não é ensino que minimize o papel do professor. Tirálo do papel de narrador não significa, de modo algum, reduzir sua importância. Ao contrário, como mediador e organizador de situações de aprendizagem centradas no aluno, ele ou ela é mais importante do que como narrador(a). 


\section{A avaliação formativa recursiva}

Ensino centrado no aluno e atividades colaborativas implicam outro tipo de avaliação. Não tem sentido, nessa abordagem, a avaliação comportamentalista, dicotômica, do tipo certo ou errado, sim ou não, aprender ou não aprender. A aprendizagem significativa é progressiva, os significados vão sendo captados e internalizados paulatinamente. A mudança conceitual não é substitutiva, como pensavam muitos pesquisadores que adotaram o modelo de Posner el al. (1982) baseado na mudança de paradigmas de Kuhn (2001) e no conflito cognitivo de Piaget (1976). Esse modelo fracassou. A mudança conceitual é evolutiva, progressiva.

Modelos alternativos coexistem na estrutura cognitiva de quem aprende e é ela ou ele quem faz a mudança, e isso ocorre progressivamente. Kelly (1963) em sua teoria da personalidade já destacava isso em um de seus corolários, o da fragmentação.

Construtos pessoais são modelos não-científicos que o ser humano constrói para dar sentido ao mundo em que vive, porém os testa frente aos eventos desse mundo como se fosse, i.e., metaforicamente, um cientista. Nesse processo, modelos alternativos podem coexistir e o abandono de uns, ou construção de outros, não ocorre de imediato, linearmente. Ao contrário, é progressivo, muito mais toulminiano do que kuhmiano. Na perspectiva da epistemologia de Stephen Toulmin (1977), conceitos estão na base da compreensão humana e eles nascem, morrem, são substituídos, adquirem outros significados, sobrevivem, enfim, evoluem. Para ele, disciplinas são populações de conceitos em evolução.

A teoria dos campos conceituais de Gérard Vergnaud (Moreira, 2004) também destaca a progressividade e a não-linearidade da aprendizagem significativa. Campo conceitual é um campo de situações-problema em distintos níveis de complexidade. Determinada matéria de ensino como a Biomecânica, por exemplo, é, nessa perspectiva, um campo de situações-problema cuja resolução envolve conceitos e procedimentos da Biologia, da Física, da Educação Física. O domínio desse campo conceitual (ou de qualquer outro) por parte do aprendiz é lento, não-linear, com rupturas e continuidades (op.cit.).

Nessa progressividade, o erro é comum e sua superação leva à aprendizagem. Aprende-se a partir do erro. Seres humanos assim procedem e aprendem. A filosofia do não, de Gastón Bachelard (1991) deixa isso claro. 
A avaliação é também, segundo Novak (2010), um dos lugares comuns do evento educativo (juntamente com o ensino, a aprendizagem, o currículo e o contexto). Mas em um ensino centrado no aluno, não na narrativa, e voltado para a captação e significados, para a aprendizagem significativa e para o aprender a aprender criticamente, a avaliação deve ser predominantemente formativa e recursiva. A avaliação formativa acompanha em que medida está ocorrendo a aprendizagem (significativa, crítica), é processual, contrariamente à somativa que é final. A recursividade permite que o aprendiz refaça as tarefas de aprendizagem, aproveite o erro como fator de aprendizagem.

\section{Aprender a aprender criticamente}

Como já foi dito, aprender a aprender faz parte do discurso educacional contemporâneo. Quando se fala em educação, nos dias atuais, independente do nível de escolarização que está sendo enfocado, é comum dizer-se que, no mundo de hoje, o importante é aprender a aprender.

Mas se Carl Rogers já dizia isso em 1969, o que há de novo na prática? Provavelmente nada! Apesar do discurso bonito, a escola continua behaviorista e calcada na narrativa. Os professores continuam narrando conhecimentos que os alunos devem reproduzir em exames locais nacionais e internacionais, e "deletar" pouco tempo depois. Essa escola não educa, treina.

Fala-se bastante também em competências, mas, em muitos casos, são os mesmos objetivos comportamentais, da época da tecnologia educacional, porém com outra roupagem.

Supondo, no entanto, que a escola buscasse promover o aprender a aprender, ou, pelo menos, que iniciativas ocorressem nessa direção, seria suficiente? Não! Teria que ser um aprender a aprender criticamente. Uma permanente busca de conhecimentos, porém de uma postura crítica.

Crítica no sentido de não aceitar, passivamente, quaisquer novos conhecimentos, sejam eles declarativos, procedimentais ou atitudinais. Se o conhecimento humano é construído, não há porque aceitá-lo sem criticidade. Esse conhecimento poderá ser substituído por outro melhor, poderá ter interesses comerciais ou ideológios subjacentes, etc.. Isso não significa negá-lo, não significa que tudo vale. Ao contrário, o 
conhecimento construído pelo homem pode ser genial, frutífero, trazer benefícios sociais,..., mas não é definitivo, não pode ser aceito acriticamente.

Como, então, facilitar o aprender a aprender criticamente?

Há várias respostas, cada uma delas procurando contribuir parcialmente para facilitar uma aprendizagem significativa crítica. Talvez o conjunto (Moreira, 2005) possa, de fato, levar o aluno a aprender a aprender criticamente.

1. Levar em conta o conhecimento prévio do aluno. Aprendemos a partir do que já sabemos. O conhecimento prévio é a variável que mais influencia a aprendizagem significativa. Não tem sentido criticidade sem aprendizagem significativa. Como ser crítico de algo que não foi aprendido significativamente.

2. Abandonar a narrativa. Simplesmente repetir a narrativa do professor não estimula a compreensão, muito menos a criticidade. Centrar o ensino nos alunos, em atividades colaborativas ou individuais, que impliquem externalização dos significados que estão sendo por eles captados. "Negociar" significados.

3. Estimular os alunos a perguntarem, ao invés de dar-lhes respostas prontas que devem ser memorizadas. Todo o conhecimento humano é construído a partir da busca de respostas a questões. É mais importante perguntar (i.e. buscar conhecimento) do que saber respostas (muitas vezes sem significado).

4. Utilizar distintos materiais educativos. Não centrar o ensino em um livro de texto, em uma apostila ou em um manual. Oferecer explicações, aceitas no contexto matéria de ensino, segundo diferentes perspectivas, distintos autores. Ater-ser a um único material (livro, apostila, manual, notas de aula) é treinamento, não educação.

5. Ensinar que o significado está nas pessoas, não nas palavras, nas coisas. Os significados são contextuais. Aqueles que são aceitos no contexto de matéria de ensino, e que são aqueles que os alunos devem captar, podem não ser os mesmos em outros contextos que não o da matéria de ensino. Promover a discriminação entre significados aceitos e não aceitos na matéria do ensino.

6. Aproveitar o erro como fator de aprendizagem. É normal errar. O conhecimento científico, por exemplo, progride corrigindo teorias erradas (que, em um dado momento, 
são bem aceitas e podem ter muitas aplicações). Incentivar os alunos a serem detectores de erros, a buscarem outras explicações.

7. Mostrar que o conhecimento humano é incerto, que depende das perguntas feitas, das definições e metáforas utilizadas. Perguntas são instrumentos de percepção, definições e metáforas são instrumentos para pensar. O conhecimento seria outro se as perguntas, as definições e as metáforas fossem outras. (Postman \& Weingartner, 1969).

8. Implementar distintas estratégias de ensino. Assim como os materiais educativos, as estratégias de ensino também devem ser diversificadas. Abandonar o quadro-de-giz (ou os slides Power Point) como única estratégia. Usar sempre a mesma estratégia torna o ensino aborrecido e não estimula a criticidade.

9. Ajudar os alunos a livrarem-se dos obstáculos epistemológicos. Incentivá-los a desaprender (no sentido de não usar) conhecimentos que podem estar bloqueando a aprendizagem significativa de outros. Desaprender, ou seja, não usar "regras que não servem", é uma estratégia de sobrevivência.

Provavelmente, o aluno que perceber que novos conhecimentos tem a ver com seus conhecimentos prévios, que aprender esses conhecimentos a partir de diferentes materiais educativos e diferentes estratégias de ensino, que captar seus significados como sendo contextuais, que entender que tais conhecimentos podem ser muito bons, mas são incertos pois dependem de perguntas, definições e metáforas, será um construtivista crítico e um permanente aprendiz. Possivelmente, não terá aprendido mecanicamente um grande repertório de respostas prontas para exames padronizados, mas terá aprendido a ser crítico, a ser epistemologicamente curioso, como diria Paulo Freire, a aprender a aprender, como proporia Carl Rogers, e começado a ser um permanente buscador de respostas e detector de erros, como preconizaria Neil Postman. Que escola fantástica seria essa!

\section{Conclusão}

Este texto começou com o modelo da narrativa e terminou propondo o abandono desse modelo. Ainda que seja consagrado, deve ser abandonado porque, quase que invariavelmente, leva a uma aprendizagem mecânica de curta duração que serve apenas 
para passar em exames. Os alunos merecem mais, a escola deve mudar, o ensino deve passar a ser centrado nos estudantes, estimulando a negociação de significados, as atividades colaborativas, a criticidade, o aprender a aprender, a educação, não simplesmente o treinamento comportamentalista. É esta a mensagem esperançosa, otimista, deste trabalho. As práticas educacionais devem mudar, os tempos são outros.

\section{Referências}

AUSUBEL, D. P. (2000). The acquisition and retention of knowledge: a cognitive view. Dordrecht: Kluwer Academic Publishers. 212p.

BACHELARD, G. (1991). A filosofia do não. Lisboa: Presença. Tradução para o português do original La philosophie du non.136p.

FREIRE, P. (1987) Pedagogia do oprimido. $18^{\mathrm{a}}$ edição. Rio de Janeiro: Paz e Terra. $184 \mathrm{p}$.

FREIRE, P. (1996). Pedagogia da autonomia: saberes necessários à prática educativa. $27^{\mathrm{a}}$ edição. São Paulo: Paz e Terra. 146p.

FINKEL, D. (2008). Dar clase de boca cerrada. Valencia: Publicaciones de la Universitat València. Tradução para o espanhol do original Teaching with your mouth shut. 292p.

GOWIN, D. B. (1981). Educating. Ithaca, N.Y.: Cornell University Press. 210p.

JOHNSON, M. Jr. (1967). Definitions and models in curriculum theory. Educational Theory, 17(2): 127-140.

KELLY, G. (1963). A theory of personality - The psychology of personal constructs. New York: W.W. Norton \& Company. 189p.

KUHN, T. (2001). A estrutura das revoluções científicas. São Paulo: Perspectiva. Tradução para o português do original The structure of scientific revolutions. $257 \mathrm{p}$.

MASINI, E.A.F. e MOREIRA, M.A. (2008). Aprendizagem significativa: condições para ocorrência e lacunas que levam a comprometimentos. São Paulo: Vetor Editora. 295p.

MATURANA, H. (2001). Cognição, ciência e vida cotidiana. Belo Horizonte: Editora da UFMG.. 203p.

MOREIRA, M.A. (2004). (Org.). A teoria dos campos conceituais de Vergnaud, o ensino de ciências e a investigação nesta área. Porto Alegre: Instituto de Física da UFRGS. 107p.

MOREIRA, M.A. (2005). Aprendizagem significativa crítica. Porto Alegre: Instituto 
de Física, UFRGS. 47p.

MOREIRA, M.A. (2006). A teoria da aprendizagem significativa e sua implementação em sala de aula. Brasília: Editora da UnB. 185p.

NOVAK, J.D. (2010). Learning, creating, and using knowledge. Concept maps as facilitative tools in schools and corporations. 2nd ed. New York and London: Routledge. 316p.

PIAGET, J. (1976). A equilibração das estruturas cognitivas. Rio de Janeiro: Zahar Editores. Tradução para o português do original L'équilibration des structures cognitives. $175 \mathrm{p}$.

POSTMAN, N. \& WEINGARTNER, C. (1969). Teaching as a subversive activity. New York: Dell Publishing Co. 219p.

ROGERS, C.R. (1969). Freedom to learn. Columbus, OH: Charles E. Merril. 358p.

ROGERS, C.R. (1971). Liberdade para aprender. Belo Horizonte: Interlivros. Tradução para o português do original Freedom to Learn. 358p.

SCHAWB, J. (1973). The practical 3: Translation into curriculum. School Review, 81(4): 501-522.

TOULMIN, S. (1977). La comprensión humana - Volumen 1: El uso colectivo y la evolución de los conceptos. Madri: Alianza Editorial. 523p.

VALADARES, J. A. E MOREIRA, M. A. (2009). Aprendizagem Significativa: sua fundamentação e implementação. Coimbra: Almedina. 132p.

VYGOTSKY, L. (1988). A formação social da mente. São Paulo: Martins Fontes. Tradução para o português do original Mind and society - The development of higher psychological process. $168 \mathrm{p}$. 